\title{
Physical and social predictors of partner abuse in women attending general practice: a cross-sectional study
}

\author{
Kelsey Hegarty, Jane Gunn, Patty Chondros and Angela Taft
}

\begin{abstract}
Background

Intimate partner abuse causes significant morbidity and mortality in women attending general practice. Currently there is insufficient evidence for screening all women but case finding of women at risk of intimate partner abuse is recommended.
\end{abstract}

Aim

To develop physical symptoms and sociodemographic indicators for partner abuse for women attending general practice.

Design of study

Descriptive, cross-sectional survey.

Setting

Thirty general practices in Victoria, Australia.

Method

A total of 1257 consecutive women attending general practice (response rate $77 \%$ ) were screened for a history of partner abuse using a self-report questionnaire. The presence of partner abuse in the last 12 months was measured by the Composite Abuse Scale.

Results

Women who reported more than two physical symptoms in the last month were more likely to report experiencing partner abuse in the last 12 months (3-5 symptoms, odds ratio $[\mathrm{OR}]=2.32,95 \%$ confidence interval $[\mathrm{Cl}]=1.55$ to $3.48 ; 6-15$ symptoms $\mathrm{OR}=3.47$. $95 \% \mathrm{Cl}=2.21$ to 5.47 ). Many individual physical symptoms were associated with partner abuse in the bivariable analysis. Multivariable analysis showed clinical indicators of partner abuse (excluding the strong association with depression) which included sociodemographic features (age, separated/divorced, low education, low income, no private insurance) and physical symptoms (diarrhoea, tiredness, chest pain).

\section{Conclusion}

Clinicians should be alert for current and past partner abuse in women who are separated/divorced, on low incomes, have poor education, or have multiple physical symptoms in the past month. Future research questions include what interventions would work for women who have been or are being abused once identified.

Keywords

domestic violence; primary care; risk factors.

\section{INTRODUCTION}

Intimate partner violence is a significant public health issue, with prevalence data similar to those for chronic diseases such as diabetes and asthma. Recent general practice studies in Australia, US, UK, and Ireland have found high lifetime physical abuse rates ranging from $23.3 \%$ to $41.0 \%$ of women, and 12-month rates from around $5 \%$ to $17 \% .^{2}$ GPs are in an ideal position to identify intimate partner violence but there is insufficient evidence for screening all women, ${ }^{3}$ and a minority of women would not want to be asked about violence in the home. ${ }^{4}$ Can predictive indicators of abuse be developed that would assist clinicians in determining who they should ask ${ }^{5}$

Associations of mental health issues with intimate partner violence have been explored in detail. ${ }^{6,7}$ In an earlier study the present authors found that the prevalence of abuse was high and that there was a strong association with depression even after adjustment was made for social indicators associated with depression. ${ }^{8}$ Limited data are available from the primary care setting about what other clinical indicators there are for partner abuse. ${ }^{9-12}$ McCauley et al previously proposed a model of risk factors for abuse consisting of sociodemographic features ( $<35$ years, separated/divorced, lack of private health insurance), psychosocial variables (low score on

K Hegarty, PhD, associate professor; J Gunn, PhD, professor; P Chondros, MSc, lecturer, Department of General Practice, University of Melbourne, Carlton; A Taft, PhD, senior research fellow, Mother and Child Health Research, La Trobe University, Melbourne, Victoria, Australia.

Address for correspondence

Dr Kelsey Hegarty, 200 Berkeley Street, Carlton, Victoria, 3053, Australia. E-mail: k.hegarty@unimelb.edu.au

Submitted: 31 October 2007; Editor's response: 16 January 2008; final acceptance: 21 February 2008.

@British Journal of General Practice.

This article was originally online first. Cite this article as: Br J Gen Pract 2008; 58: 484-487. Advance online publication. DOI: 10.3399/bjgp08X299245 
mental health dimension SF-36, alcohol abuse, suicide), and physical symptoms (for example, injuries, diarrhoea, vaginal discharge). ${ }^{10}$

This article expands on the authors' previous work on depression and abuse ${ }^{8}$ to explore the association of clinical indicators for partner abuse in women attending their GP. Specifically, it explores physical symptoms and sociodemographic factors as predictors of partner abuse for women attending general practice.

\section{METHOD}

The methods, ethical approval, and sample size of the current study have been described previously. ${ }^{8}$ In brief, GPs who had previously volunteered for a women's health educational programme were stratified into non-urban and metropolitan regions, and selected at random until 30 GPs were recruited. From August to December 2000, a project worker in the waiting room invited all women (16-50 years) presenting for themselves, or with relatives, to complete a questionnaire. Women were excluded if they did not have the mental or physical capacity to answer the questionnaire, could not read or write English, or were attending closely with a male partner.

The questionnaire included sociodemographic data, Composite Abuse Scale (CAS), ${ }^{13}$ Beck Depression Inventory $(\mathrm{BDI})^{8}$ or Edinburgh Postnatal Depression Scale (EPDS, if postnatal), ${ }^{14}$ SF-36, ${ }^{15}$ self-report of depression and anxiety, and a list of common physical symptoms presenting in general practice, based on previous research in Australian general practices. ${ }^{16}$ Three physical symptoms were also included (injuries, diarrhoea, and vaginal discharge) from a similar previous study in four US primary care clinics. ${ }^{10}$ The main outcome of whether women were probably abused in the past 12 months was measured using the CAS, a 30-item, well-validated measure for primary care.

Women who were not in an adult intimate relationship in the last 12 months were excluded from the analysis. Logistic regression, using the survey commands in Stata Statistical software (version 9) to adjust for the clustering effect, was used to examine the association between women identified as probably abused and not abused, with BDI or EPDS scores, self-report of depression, anxiety and physical symptoms, patient characteristics, and SF-36 composite scores for physical and mental health. Stepwise logistic regression was used to fit the model of risk factors for abuse using the 17 self-reported physical symptoms in the past 4 weeks and sociodemographic factors. Measures of probable depression (BDI or EPDS scores) and self-reported depression and anxiety symptoms were not included in the final multivariable model, as the research aimed

\section{How this fits in}

There are limited data from primary care about physical symptoms and their

association with intimate partner violence. The majority of studies concentrate on physical violence and use data from a small number of general practices. This study of 30 Australian general practices shows that multiple physical symptoms, psychosocial symptoms, and sociodemographic characteristics are predictors of intimate partner violence for women attending general practice. Researchers should measure partner abuse in medically unexplained physical symptom studies. Doctors should look out for partner abuse in women with multiple physical symptoms.

to specifically examine the physical symptoms that are associated with probable abuse. However, to investigate the relative importance of psychosocial and physical symptoms, the effect on the final model of including self-reported depression and anxiety symptoms was examined. Risk factors were included in the model if they exhibited a moderate level of association $(P<0.1)$.

\section{Table 1. Association of partner abuse with sociodemographic characteristics ${ }^{a}$ and mental health factors for women attending general practice $(n=942)$.}

\begin{tabular}{|c|c|c|c|c|}
\hline & $\begin{array}{l}\text { Abused } \\
(n=163)\end{array}$ & $\begin{array}{l}\text { Not abused } \\
(n=779)\end{array}$ & & \\
\hline & $n(\%)$ & $n(\%)$ & OR & $95 \% \mathrm{Cl}$ \\
\hline \multicolumn{5}{|l|}{ Sociodemographic characteristics } \\
\hline Age 35 years $(n=938)$ & 95 (58.6) & $349(45.0)$ & 1.73 & 1.18 to 2.54 \\
\hline $\begin{array}{l}\text { Education level: left school } \\
\text { before year } 10(n=941)\end{array}$ & $21(13.0)$ & $52(6.7)$ & 2.08 & 1.39 to 3.11 \\
\hline $\begin{array}{l}\text { Marital status: separated, widowed } \\
\text { or divorced }\end{array}$ & $14(8.6)$ & $22(2.8)$ & 3.23 & 1.75 to 5.97 \\
\hline $\begin{array}{l}\text { Income source: }{ }^{c} \text { pension or benefit } \\
(n=940)\end{array}$ & $25(15.4)$ & $32(4.1)$ & 4.25 & 2.21 to 8.18 \\
\hline No private health insurance $(n=933)$ & $82(51.3)$ & $237(30.7)$ & 2.38 & 1.61 to 3.52 \\
\hline \multicolumn{5}{|l|}{ Depression factors } \\
\hline $\begin{array}{l}\text { Probable depression in past week }{ }^{d} \\
(n=917)\end{array}$ & $52(32.7)$ & $73(9.6)$ & 4.56 & 3.16 to 6.54 \\
\hline Suicidal thoughts $(n=919)$ & $8(5.0)$ & $5(0.7)$ & 7.94 & 2.58 to 24.40 \\
\hline \multicolumn{5}{|l|}{ SF-36 composite scale } \\
\hline & $\begin{array}{l}\text { Abused } \\
(n=150)\end{array}$ & $\begin{array}{l}\text { Not abused } \\
(n=716)\end{array}$ & & \\
\hline & Mean (SD) & Mean (SD) & Diff & $95 \% \mathrm{Cl}$ \\
\hline Physical health & $49.20(9.86)$ & $49.65(10.51)$ & -0.45 & -2.3 to 1.39 \\
\hline Mental health & $36.40(8.71)$ & $46.03(10.93)$ & -9.6 & -11.2 to -8.0 \\
\hline
\end{tabular}

a Small numbers $(<10)$ of Aboriginal and Torres Straight islander, and people with a nonEnglish-speaking background precluded their inclusion in analysis. ${ }^{b} N i n e$ hundred and eighty-eight women were in a current intimate relationship of whom 46 had not completed the Composite Abuse Scale. 'Only one income measure was included, but household income less AU\$500 per week and unemployed seeking work had similar associations with abuse. ${ }^{d}$ Probable depression measured as Edinburgh Postnatal Depression Scale total $>12$ or Beck Depression Inventory total $>16$. OR = odds ratio calculated using logistic

regression, confidence intervals adjusted for clustering effect. $S D=$ standard deviation. Diff = difference in means calculated using linear regression, confidence intervals adjusted for clustering effect. 


\begin{tabular}{|c|c|c|c|c|}
\hline \multirow{2}{*}{$\begin{array}{l}\text { Self-reported symptoms in } \\
\text { the past } 4 \text { weeks }\end{array}$} & $\begin{array}{l}\text { Abused } \\
(n=158)\end{array}$ & $\begin{array}{l}\text { Not abused } \\
(n=767)\end{array}$ & \multirow[b]{2}{*}{ OR } & \multirow[b]{2}{*}{$95 \% \mathrm{Cl}$} \\
\hline & $n(\%)$ & $n(\%)$ & & \\
\hline \multicolumn{5}{|c|}{ Total number of self reported physical symptoms (out of 17$)^{\mathrm{a}}$} \\
\hline $0-2$ & $48(30.4)$ & $408(53.2) 1.0$ & & \\
\hline $3-5$ & $74(46.8)$ & $271(35.3)$ & 2.32 & 1.55 to 3.48 \\
\hline $6-15$ & $36(22.8)$ & $88(11.5)$ & 3.48 & 2.21 to 5.47 \\
\hline \multicolumn{5}{|c|}{ Self-reported symptoms (not mutually exclusive) } \\
\hline Depression & $72(45.6)$ & $144(18.8)$ & 3.62 & 2.64 to 4.97 \\
\hline Chest pain & $17(10.8)$ & $27(3.5)$ & 3.30 & 1.78 to 6.15 \\
\hline Anxiety & $57(36.1)$ & $131(17.1)$ & 2.74 & 1.88 to 3.98 \\
\hline Fever & $21(13.3)$ & $45(5.9)$ & 2.46 & 1.27 to 4.76 \\
\hline $\begin{array}{l}\text { Broken bones, sprains, } \\
\text { or serious cuts }\end{array}$ & $7(4.4)$ & $16(2.1)$ & 2.18 & 0.76 to 6.20 \\
\hline Tiredness & $122(77.2)$ & $489(63.8)$ & 1.93 & 1.29 to 2.87 \\
\hline Chronic headaches & $39(24.7)$ & $113(14.7)$ & 1.90 & 1.21 to 2.98 \\
\hline Vaginal discharge & $25(15.8)$ & $71(9.3)$ & 1.84 & 1.14 to 2.97 \\
\hline Diarrhoea & $32(20.3)$ & 95 (12.4) & 1.80 & 1.18 to 2.74 \\
\hline Chronic abdominal pains & $18(11.4)$ & $53(6.9)$ & 1.73 & 1.00 to 3.01 \\
\hline Throat problems & $39(24.7)$ & $123(16.0)$ & 1.72 & 1.17 to 2.51 \\
\hline Nasal congestion/sneeze & $54(34.2)$ & $179(23.3)$ & 1.71 & 1.17 to 2.49 \\
\hline Difficulty sleeping & $83(52.5)$ & $308(40.2)$ & 1.65 & 1.15 to 2.36 \\
\hline Back problems & $55(34.8)$ & $194(25.3)$ & 1.58 & 1.00 to 2.50 \\
\hline Dizziness & $31(19.6)$ & $104(13.6)$ & 1.56 & 1.01 to 2.40 \\
\hline Cough & 45 (28.5) & $164(21.4)$ & 1.46 & 0.96 to 2.23 \\
\hline Rash & $14(8.9)$ & $51(6.6)$ & 1.36 & 0.81 to 2.30 \\
\hline Ear pain & $11(7.0)$ & $61(8.0)$ & 0.87 & 0.46 to 1.62 \\
\hline High blood pressure & $5(3.2)$ & $39(5.1)$ & 0.61 & 0.25 to 1.47 \\
\hline
\end{tabular}

${ }^{a}$ Total number excludes self-reported symptoms of depression and anxiety. OR = odds ratio calculated using logistic regression, confidence intervals adjusted for clustering effect.

\section{RESULTS}

The representativeness of the participating GPs and the women has been described in detail previously. ${ }^{8}$ In summary, the GPs were more likely to be female, work part time, and to have graduated more recently compared with Australian population data. The participating women were more likely to be older and English speaking, and there was lower representation of women of low-income households, limited training

\begin{tabular}{|c|c|c|}
\hline Risk factor & OR & $95 \% \mathrm{Cl}$ \\
\hline \multicolumn{3}{|l|}{ Sociodemographic factors } \\
\hline Marital status: separated, widowed or divorced & 2.62 & 1.17 to 5.80 \\
\hline Age 35 years & 1.65 & 1.03 to 2.63 \\
\hline Income source: pension or benefit & 2.58 & 1.25 to 5.32 \\
\hline No private health insurance & 1.66 & 1.08 to 2.54 \\
\hline Education level: left school before year 10 & 1.98 & 1.14 to3.44 \\
\hline \multicolumn{3}{|l|}{ Self-reported physical symptoms in past 4 weeks } \\
\hline Diarrhoea & 1.65 & 1.06 to 2.57 \\
\hline Tiredness & 1.98 & 1.26 to 3.09 \\
\hline Chest pain & 2.71 & 1.37 to 5.34 \\
\hline
\end{tabular}

Number of physical symptoms, measures of depression (using BDI and EPDS), and selfreported depression and anxiety were not included in the multivariable model as the study aimed to examine the particular physical symptoms that are associated with probable abuse. $\mathrm{OR}=$ odds ratio. and in unskilled occupations compared with Australian population data.

\section{Associations of partner abuse}

Women who scored in the 'probably-abused' range were more likely to be young ( $<35$ years), divorced or separated, have less education, and be on a pension or benefit (Table 1). Women who were currently abused were much more likely to be probably depressed, to have experienced suicidal thoughts, and to score low on the mental health scale of the SF-36 (Table 1).

Women who reported a greater number of physical symptoms were more likely to report experiencing partner abuse in the last 12 months (Table 2). This association remained significant after adjusting for the above sociodemographic variables (3-5 symptoms, odds ratio $[\mathrm{OR}]=2.24,95 \%$ confidence interval $[\mathrm{Cl}]=$ 1.48 to 3.39 ; $6-15$ symptoms $\mathrm{OR}=3.28,95 \% \mathrm{Cl}=$ 2.02 to 5.34). Many individual physical symptoms were associated with partner abuse in the bivariable analysis (Table 2).

\section{Risk factor model}

Multivariable analysis showed that the psychological variables (probable depression BDI or EPDS, SF-36 mental health score) had the strongest association with abuse. ${ }^{8}$ Excluding the psychological variables, a risk factor model of sociodemographic and physical symptom clinical indicators of partner abuse (Table 3) included sociodemographic features (young age, separated/divorced, low education, low income, no private insurance), and physical symptoms (diarrhoea, tiredness, and chest pain). When the self-reported symptoms of depression and anxiety were both included in the multivariable model, chest pain was the only physical symptom that remained, while all sociodemographic variables remained significant. When self-reported depression symptoms or the SF36 mental health score were included in multivariable regression analysis, the symptom of tiredness was no longer significant. If the self-reported symptom of anxiety was added, then the physical symptom of diarrhoea was no longer significant. These findings highlight the nature of the physical symptoms and their association with depression and anxiety symptoms.

\section{DISCUSSION}

\section{Summary of main findings}

There are limited data from primary care looking at the association between risk factors and intimate partner violence and abuse. ${ }^{9-12}$ The current authors' previous work showed a strong association between depression and partner abuse existing even after adjustment was made for social indicators associated with depression. ${ }^{8}$ Mental health issues are the strongest indicator for clinicians of an association with partner abuse for 
women attending general practice.${ }^{6,7}$ However, in this study, multiple physical symptoms were also strongly associated with intimate partner abuse (in particular, tiredness, diarrhoea, and chest pain). Further, these particular symptoms also have an association with depression and anxiety symptoms. In addition, partner abuse is associated with women who are young, separated or divorced, who have no private health insurance, or low education or income.

\section{Strengths and limitations of the study}

Limitations of this study include its cross-sectional nature, precluding causal inference, and the use of selfreport to measure outcomes. The strength of the study is the large variety of general practices from which the sample was derived, and the multidimensional nature of the measure of abuse used.

\section{Comparison with existing literature}

It is clear from this study and others that a combination of sociodemographic features, mental health issues, and an increasing number of common psychosocial physical symptoms should alert clinicians to the possibility of partner abuse..$^{9-12}$ It is unlikely that the specific physical symptoms found in this model or that of McCauley et $a^{p, 10}$ are the only important symptoms, rather they represent the types of psychosocial presentations that are common when women feel stressed. Further, the relationship between medically unexplained symptoms, chronic pain, ${ }^{17}$ depression, and intimate partner violence is beginning to be explored..$^{18}$

\section{Implications for future research and clinical practice}

Clinicians treating women presenting with multiple psychosocial physical symptoms should consider whether to sensitively inquire about a history of current or past abuse, as this is what abused women say they want of their health professionals. ${ }^{19,20}$ There is insufficient evidence to promote screening of all women; ${ }^{21}$ however, recent evidence has emerged that training can increase active questioning about partner abuse, ${ }^{22}$ and there are several international screening trials underway.

\section{Funding body}

The Department of Health, Housing and Community Services, Canberra, Australia funded this project through the General Practice Evaluation Program. All researchers are independent of these funders (GPEP No 859)

\section{Ethical approval}

Ethical approval was given by the University of Melbourne (000113)

\section{Competing interests}

The authors have stated that there are none

\section{Acknowledgements}

We would like to thank Rhonda Small who gave advice on the design of the study; Nancy Carabella, Christina Pitter and Jacinta Lee who administered the project; all the GPs and women who participated; Cate Nagle who helped with coding; and the research assistants who collected the data Tessa Keegal, Deidre Harrison, Desiree Green, Amanda Webb, Caroline Curtis, Colleen Nordstrom, Ann Vlass, Sally Ann Avery, Elke Varga, and Prue Forbes.

Discuss this article

Contribute and read comments about this article on the Discussion Forum: http://www.rcgp.org.uk/bjgp-discuss

\section{REFERENCES}

1. Watts C, Zimmerman C. Violence against women: global scope and magnitude. Lancet 2002; 359(9313): 1232-1237.

2. Hegarty K. What is domestic violence and how common is it? In: Roberts G, Hegarty K, Feder G (eds). Intimate partner abuse and health professionals: new approaches to domestic violence. London: Elsevier, 2006: $19-40$.

3. Ramsay J, Richardson J, Carter YH, et al. Should health professionals screen women for domestic violence? Systematic review. BMJ 2002; 325(7359): 314-317.

4. Boyle A, Jones P. The acceptability of routine inquiry about domestic violence towards women: a survey in three healthcare settings. $\mathrm{Br} J \mathrm{Gen}$ Pract 2006; 56(525): 258-261.

5. Zachary M, Mulvihill M, Burton W, Goldfrank L. Domestic abuse in the emergency department: can a risk profile be defined? Acad Emerg Med 2001; 8(8): 796-803.

6. Golding J. Intimate partner violence as a risk factor for mental disorders: a meta-analysis. J Fam Violence 1999; 14(2): 99-132.

7. Coid J, Petruckevitch A, Chung W, et al. Abusive experiences and psychiatric morbidity in women primary care attenders. Br J Psychiatry 2003; 183: 332-339.

8. Hegarty K, Gunn J, Chondros P, Small R. Association of depression and partner abuse in women attending general practice: a cross sectional survey. BMJ 2004; 328(7440): 621-624.

9. Coker AL. Frequency and correlates of intimate partner violence by type physical, sexual and psychological battering. Am J Public Health 2000; 90(4): 553-559.

10. McCauley J, Kern DE, Kolodner K, Smith J. The 'battering syndrome': prevalence and clinical characteristics of domestic violence in primary care internal medicine practices. Ann Intern Med 1995; 123(10): 737-746.

11. Nicolaidis C, Curry M, McFarland B, Gerrity M. Violence, mental health and physical symptoms in an academic internal medicine practice. J Gen Intern Med 2004; 19(8): 893-895.

12. Ruiz-Perez I, Plazaola-Castano J. Intimate partner violence and mental health consequences in women attending family practice in Spain. Psychosom Med 2005; 67(5): 791-797.

13. Hegarty K, Bush R, Sheahan M. The Composite Abuse Scale: further development and assessment of reliability in two clinical settings. Violence Vict 2005; 20(5): 529-547.

14. Murray L, Carothers AD. The validation of the Edinburgh Post-natal Depression Scale on a community sample. Br J Psychiatry 1990; 157: 288-290.

15. McHorney CA, Ware JE, Lu JFR, Sherbourne CD. The MOS 36-item short form health survey (SF-36): III. Tests of data quality, scaling assumptions and reliability across diverse patient groups. Med Care 1994; 32(1): 40-66.

16. Britt H, Sayer GP, Miller GC, et al. General practice activity in Australia 1998-99. AIHW Cat. No. GEP, 2nd edn. Canberra: Australian Institute of Health and Welfare, 1999.

17. Lo Fo Wong S, Wester F, Mol S, et al. Utilisation of health care by women who have suffered abuse: a descriptive study on medical records in family practice. Br J Gen Pract 2007; 57(538): 396-400.

18. Katon W, Sullivan M, Walker E. Medical symptoms without identified pathology: relationship to psychiatric disorders, childhood and adult trauma and personality traits. Ann Intern Med 2001; 134(9): 917-925.

19. Feder G, Hutson M, Ramsay J, Taket A. Women exposed to intimate partner violence: expectations and experiences when they encounter health care professionals: a meta-analysis of qualitative studies. Arch Intern Med 2006; 166(1): 22-37.

20 Feder G. Responding to intimate partner violence: what role for general practice? Br J Gen Pract 2006; 56(525): 243-244.

21. Nelson HD, Nguyen P, McInerney Y, Klein J. Screening women and elderly adults for family and intimate partner violence: a review of the evidence for the US Preventive Services Task Force. Ann Intern Med 2004; 140(5): 382-386.

22. Lo Fo Wong S, Wester F, Mol S, Lagro-Janssen T. Increased awareness of intimate partner abuse after training: a randomised controlled trial. $\mathrm{Br} \mathrm{J}$ Gen Pract 2006; 56(525): 249-257. 